August 2008

\title{
The minimally invasive treatment of ureteropelvic junction obstruction: a review of our experience during the last decade.
}

\author{
Brent V. Yanke \\ Thomas Jefferson University \\ Costas D. Lallas \\ Thomas Jefferson University \\ Christopher Pagnani \\ Thomas Jefferson University \\ David E. McGinnis \\ Thomas Jefferson University \\ Peimettrihis and Bagelteibnal works at: https://jdc.jefferson.edu/urologyfp \\ Thomas Jefferson University \\ Part of the Urology Commons \\ Let us know how access to this document benefits you
}

\section{Recommended Citation}

Yanke, Brent V.; Lallas, Costas D.; Pagnani, Christopher; McGinnis, David E.; and Bagley, Demetrius $\mathrm{H}$., "The minimally invasive treatment of ureteropelvic junction obstruction: a review of our experience during the last decade." (2008). Department of Urology Faculty Papers. Paper

2.

https://jdc.jefferson.edu/urologyfp/2

This Article is brought to you for free and open access by the Jefferson Digital Commons. The Jefferson Digital Commons is a service of Thomas Jefferson University's Center for Teaching and Learning (CTL). The Commons is a showcase for Jefferson books and journals, peer-reviewed scholarly publications, unique historical collections from the University archives, and teaching tools. The Jefferson Digital Commons allows researchers and interested readers anywhere in the world to learn about and keep up to date with Jefferson scholarship. This article has been accepted for inclusion in Department of Urology Faculty Papers by an authorized administrator of the Jefferson Digital Commons. For more information, please contact: JeffersonDigitalCommons@jefferson.edu. 
The Minimally Invasive Treatment of Ureteropelvic Junction Obstruction: A Review of Our Experience During the Last Decade

Brent V. Yanke,* Costas D. Lallas, $†$ Christopher Pagnani, David E.

McGinnis and Demetrius H. Bagleył

From the Department of Urology, Thomas Jefferson University, Philadelphia, Pennsylvania

* CR Bard Fellow in Endourology and Laparoscopy.

$\dagger$ Correspondence: Department of Urology, Thomas Jefferson University Hospital, 1025

Walnut St., Ste 1100, Philadelphia, Pennsylvania 19107 (telephone: 215-955-6961; FAX:

215-923-1884; e-mail: costas.lallas@ jefferson.edu ).

$\ddagger$ Financial interest and/or other relationship with ACMI, Bard and Cook.

\begin{abstract}
Purpose:

The minimally invasive treatment of ureteropelvic junction obstruction has evolved during the last decade from endoscopic to laparoscopic and robotic. We review our 10-year experience with ureteropelvic junction obstruction, and report on our experience and followup.

Materials and Methods:

We reviewed all patients treated during the last 10 years. There were 294 procedures performed with complete records on 273 patients including 128 retrograde endopyelotomies, 116 laparoscopic pyeloplasties and 29 robotic pyeloplasties. Technique for each procedure is reviewed. Statistical analysis was performed on all results. Variables evaluated were gender, age (younger than 41 vs 41 years or older), side (right or left), presence of crossing vessels, presence of a high insertion, primary or secondary procedure and whether prior endopyelotomy or pyeloplasty had been performed.
\end{abstract}

Results:

Mean followup for endopyelotomy, laparoscopic pyeloplasty and robotic pyeloplasty was 20,20 and 19 months, respectively, with success rates of $60.2 \%, 88.8 \%$ and $100 \%$, respectively. On univariable analysis only the presence of crossing vessels or a high insertion was significant for laparoscopic pyeloplasty. On multivariable analysis age was significant for endopyelotomy and the presence of crossing vessels was significant for pyeloplasty. On Kaplan-Meier analysis failures were noted to occur after 5 years in both groups.

Conclusions:

Laparoscopic pyeloplasty and robotic pyeloplasty are superior minimally invasive 
treatments for ureteropelvic junction obstruction. However, endopyelotomy can be used for select patients. Because of late failures patients who undergo either of these procedures should receive long-term followup.

Key Words: ureteral obstruction, laparoscopy, robotics

In the last decade open pyeloplasty has largely been replaced by minimally invasive approaches for the treatment of ureteropelvic junction obstruction in adults. In the 1980s antegrade endopyelotomy by cold knife performed through a nephrostomy tract was first reported. This technique offered the advantage of being able to treat considerable renal calculus burdens during the same procedure. However, it requires the establishment of a nephrostomy tract before the endopyelotomy can be performed as well as longer hospital stays. Ureteroscopic endopyelotomy soon followed, initially described as pyelolysis using the rigid ureteroscope. It was difficult to reach the ureteropelvic junction with a rigid ureteroscope and the availability of flexible instruments prompted the wider acceptance of flexible ureteroscopic endopyelotomy.

Since the first published reports in 1993 laparoscopic pyeloplasty has proven to be safe and effective with outcomes comparable to the open procedure and superior to endopyelotomy. $^{4-6}$ One drawback has been the relatively steep learning curve for this procedure. In particular, intra-corporeal suturing with laparoscopic instruments can be technically demanding.

The da Vinci® Surgical System has enabled these laparoscopic techniques to be performed with greater ease and, in the process, has expanded the use of laparoscopy in urology. The known advantages of the robotic system to the surgeon allow for more efficient intracorporeal suturing. This has led to shorter operative times with similar success rates compared to the straight laparoscopic approach. ${ }^{7,8}$ We present our experience with the minimally invasive treatment and long-term followup of UPJO.

\section{MATERIALS AND METHODS}

After institutional review board approval charts of all patients treated for UPJO at our institution from 1995 to 2006 were retrospectively reviewed. A total of 294 patients underwent minimally invasive treatment. The initial diagnosis of UPJO was based on subjective criteria such as flank pain and pyelonephritis or incidental findings from radiological evaluation of unrelated medical conditions. Radiological verification was 
obtained by excretory urography or CT urography. In addition, all patients had preoperative diuretic renogram to establish baseline renal function including split renal function and the degree of obstruction. Evaluation for crossing vessels was performed by $\mathrm{CT}$ angiogram or endoluminal ultrasound. For patients undergoing pyeloplasty indwelling stents were removed 2 to 3 weeks before the procedure. It is our belief that indwelling stents increase edema and UPJ wall thickening, making for a more difficult dissection and reconstruction of the UPJ.

Our technique of endopyelotomy has been described previously. ${ }^{9}$ We begin with a retrograde pyelogram which demonstrates the length of the UPJ narrowing and identifies any additional ureteral strictures. This is followed by endoluminal ultrasound using a $6 \mathrm{Fr}$ probe. We can identify the presence of crossing vessels noting their size and location as well as a septum which indicates a high ureteral insertion into the UPJ. ${ }^{10,11}$ After placement of a safety wire a flexible ureteroscope is introduced and the UPJ is visualized. The information collected from these imaging studies determines the site and length of the incision. Endopyelotomies early in our series were performed using a small diameter electrode, but this has largely been replaced by the 200 micron holmium laser fiber with preferred energy and frequency settings of 1.2 to 1.5 Joules per pulse and 10 to 15 Hertz, respectively. The incision is made through the entire thickness of the ureter. Finally a balloon catheter is deployed to calibrate the incision and open the adventitia. A ureteral stent is then placed which is removed approximately 6 to 8 weeks after surgery.

Positioning and exposure for LP and RP are essentially the same. The patient is positioned in a modified 45-degree flank position. Cystoscopy is performed to pass a guidewire into the proximal ureter for later stent placement. A standard 4 trocar arrangement is used which includes a $12 \mathrm{~mm}$ periumbilical trocar for the laparoscope anda5mm assistant trocar. LP uses a pair of $5 \mathrm{~mm}$ working trocars while RP replaces these with a pair of $8 \mathrm{~mm}$ da Vinci trocars. Dissection begins with medial reflection of the colon and is followed by isolation of the ureter at a location inferior to the lower pole of the kidney. The ureter is mobilized, and traced up to the UPJ and renal pelvis. If present, crossing vessels are identified and preserved. Once the UPJ is fully dissected dismemberment is performed and the affected segment is resected. Crossing vessels are repositioned posterior to the anastomosis and after ureteral spatulation the anastomosis is completed using 4-zero polyglactin sutures over an indwelling ureteral stent. The stent remains in place for 6 weeks.

Currently for all patients a diuretic renogram is performed at 3 and 6 months, and 1 year postoperatively. Additionally, if the initial renogram is normal an ultrasound is occasionally used afterward if the patient remains asymptomatic. A renal ultrasound or diuretic renogram is also obtained annually thereafter. Successful repair is defined as resolution of preoperative symptoms and improvement or stability of radiographic parameters. When we evaluate our patients using $t^{1} / 2$ criteria success is defined with $t^{1} / 2$ less than 10 minutes (strict success) or 10 to 20 minutes (relative success). When the renogram demonstrates delayed drainage (more than 20 minutes) but shows relative improvement in 
the $t 1 / 2$ compared to preoperative values, as long as the patient remains asymptomatic and the split function improves or stays stable, then the repair is also considered patent.

Alternatively if the $t^{1 / 2}$ demonstrates relative success (10 to 20 minutes) and the patient has a relapse of symptoms and a decline in function by diuretic renogram, the repair is considered a failure. Cox regression hazard ratios and Kaplan-Meier failure-free estimates were determined for the endopyelotomy and LP populations.

\section{RESULTS}

We reviewed 145 retrograde endopyelotomies, 120 LPs and 29 robotic assisted laparoscopic pyeloplasties (RPs) with followup available on 128 (88.3\%), $116(96.7 \%)$ and $29(100 \%)$, respectively. Patient characteristics of each group with followup are presented in table 1 . The number of each procedure performed by year is presented in figure 1. Median followup (range) for the endopyelotomy, LP and RP groups was 20 (1 to 165), 20 (1 to 87 ) and 19 (13 to 25 ) months, respectively. The overall success rate for the endopyelotomy group was $60.2 \%$ and for the LP group was $88.8 \%$. There have yet to be failures in the RP group. Univariable and multivariable analysis is presented in table 2. On univariable analysis there was no difference in success for the endopyelotomy group when examining sex, presence of crossing vessels or high insertion, primary vs secondary repair, side or age. In the LP group the only statistically significant differences on univariable analysis were for the presence of crossing vessels and high insertion ( $p=0.028$ for each). On multivariable analysis undergoing LP was statistically significant $(\mathrm{p}<0.001)$ as was age 41 years or older $(\mathrm{p}=0.003)$. In the endopyelotomy group age was the only significant variable $(\mathrm{p}=0.014)$ while the presence of crossing vessels was the only significant variable in the LP group ( $\mathrm{p}=0.028)$. Kaplan-Meier 1, 3 and 7-year failure-free estimates for endopyelotomy were $82 \%, 62 \%$ and $50 \%$, and for LP were $93 \%, 86 \%$ and $76 \%$, respectively ( $\mathrm{p}<0.001$ ) (fig. 2 ). In the RP group $31 \%$ of the repairs were for secondary UPJO and 20 patients overall were found to have crossing vessels. Because of shorter followup these patients were not included in the statistical analysis.

\section{DISCUSSION}

We found the success rate for LP to be significantly greater than for endopyelotomy. However, while a majority of treatment failures occurred within the first 2 years for both groups there were still failures as followup continued. As a result success rates were lower than has generally been described, in part because many studies have short 1 to 2-year followup. ${ }^{4,5,12}$ Our findings are notably similar to those of Dimarco et al, who found estimated 3, 5 and 10-year recurrence-free survival rates for endopyelotomy to be $63 \%$, $55 \%$ and $41 \%$, respectively, compared to $85 \%, 80 \%$ and $75 \%$ for pyeloplasty $(\mathrm{p}<0.001)$ (fig. 3). 
The implications of these findings are far-reaching. For endopyelotomy and pyeloplasty we contend that patients should have long-term followup, which is contradictory to what has been recommended in the past. ${ }^{14,15}$ In addition, we have changed our followup for endopyelotomy and pyeloplasty to be more consistent with our findings. Although we still see patients every 3 to 6 months in the year after treatment with a functional study, we now see them annually thereafter with renal ultrasound and diuretic renogram, if needed, to evaluate for new hydronephrosis, cortical loss or return of symptoms. When evaluating $t^{1} / 2$ we consider relative improvement in addition to strict (less than 10 minutes) and relative (10 to 20 minutes) success. There were 2 patients in the endopyelotomy group and 1 in the pyeloplasty group who had a $\mathrm{t}^{1} / 2$ that was persistently more than 20 minutes after repair. In all 3 patients this represented an improvement compared to preoperative values and the patients remained asymptomatic with stable differential function. These repairs were regarded as successful. Alternatively 1 patient in each group had a $t^{1 / 2}$ that was 10 to 20 minutes after repair but had a postoperative return of symptoms and a decline in renal function. Although the $t^{1 / 2}$ showed relative success, both of these cases were considered failures.

Our identification of long-term failures is especially relevant for the RP group, in which no failures have been recognized with relatively short followup. All of these patients have demonstrated strict or relative success by postoperative $t \frac{1}{2}$ values. However, based on the previously mentioned failure-free estimates it would not be unreasonable to expect failures as surveillance continues.

On multivariable analysis the presence of crossing vessels led to a statistically significant improvement in success in the LP group. Because of prior experience we did not treat these patients with endopyelotomy, thus selecting out those at high risk for failure. An explanation for the statistical significance in LP could be that crossing vessels provide a definitive target for repair. This would allow for pinpoint identification and reconstruction of the affected area leading to improved success rates. We routinely transpose any lower pole crossing vessels lateral to our repair, although the necessity of this has recently been called into question. ${ }^{16}$ Regardless of this controversy, like others we contend that crossing vessels, when present, represent a clear etiology of obstruction that needs to be addressed for a repair to be successful. ${ }^{17,18}$ In addition, we found that age younger than 41 years was significant for success in endopyelotomy. However, this was not the case for the LP group. When considering treatment options with respect to age we choose LP for younger patients because of better long-term success. Other variables that we did not evaluate which likely would have also proved significant and have also been recognized by other groups are severe hydronephrosis and preoperative renal function.

Other single institution comparisons of endopyelotomy and pyeloplasty for UPJO have been made. ${ }^{12,13,19}$ However, in 2 of these reports antegrade endopyelotomy was the endoscopic method used. ${ }^{12,13}$ In the series by Rassweiler et al laser endopyelotomy was 
used with a success rate of $78.3 \% .^{19}$ However, their Kaplan-Meier estimation of success included a time course that extended out to half of what we reported. Arguably with longer followup they would have realized more failures and they actually concluded at the end of their study that, even with careful patient selection, endopyelotomy was inferior to pyeloplasty in direct comparison. Our series, to our knowledge the largest reported with long followup, confirms this conclusion. This can be inferred from our practice patterns during the last decade (fig. 1). Currently the only patients for whom we are recommending endopyelotomy primarily are those who have an absence of crossing vessels and severe hydronephrosis (detected intraoperatively by endoluminal ultrasound and retrograde pyelogram, respectively), and who are otherwise poor surgical candidates or refuse a more invasive procedure. Still, with low morbidity and high success rates pyeloplasty (laparoscopic or robotic) is the definitive minimally invasive procedure for UPJO, and any patient younger than 40 years with salvageable renal function, regardless of UPJ pathology, is treated with either of these operations at our institution. Other putative benefits of LP/RP include the ability to treat patients with UPJO with aberrant anatomy, different degrees of hydronephrosis or concomitant calculi. Furthermore, with the advent of robotic technology, which may not add anything to LP in experienced hands but will help to disseminate it among less skilled urologists, the procedure will become more widespread. At our institution the decision between LP and RP is surgeon dependent, and is not influenced by individual patient or pathological considerations.

\section{CONCLUSIONS}

While laparoscopic pyeloplasty continues to have significantly improved outcomes compared to endopyelotomy, anticipated rates of success appear to be less than previously reported. It is clear that remote failures do occur in both groups and, therefore, these patients should be continually followed. However, with long-term followup pyeloplasty remains superior. The presence of crossing vessels is a positive predictor for patients who undergo pyeloplasty and patients with this UPJ pathology should be treated with this procedure. Finally robotic pyeloplasty parallels the success of LP and will likely make this procedure more common, thus further minimizing the role of endopyelotomy.

\section{ACKNOWLEDGMENTS}

Statistical analysis for this article was performed by the Department of Biostatistics at our institution.

\section{ABBREVIATIONS AND ACRONYMS}

$$
\begin{aligned}
& \mathrm{CT}=\text { computerized tomography } \\
& \mathrm{LP}=\text { laparoscopic pyeloplasty } \\
& \mathrm{RP}=\text { robotic pyeloplasty } \\
& \mathrm{t}^{1 / 2}=\text { half-time }
\end{aligned}
$$


$\mathrm{UPJ}=$ ureteropelvic junction

$\mathrm{UPJO}=$ ureteropelvic junction obstruction

\section{REFERENCES}

1 Smith AD: Percutaneous ureteral surgery and stenting. Urology 1984; 23: 37.

2 Inglis JA and Tolley DA: Ureteroscopic pyelolysis for pelviureteric junction obstruction. Br J Urol 1986; 58: 250.

3 Bagley DH, Huffman J, Lyon E and McNamara T: Endoscopic ureteropyelostomy: opening the obliterated ureteropelvic junction with nephroscopy and flexible ureteropyeloscopy. J Urol 1985; 133: 462.

4 Bauer JJ, Bishoff JT, Moore RG, Chen RN, Iverson AJ and Kavoussi LR: Laparoscopic versus open pyeloplasty: assessment of objective and subjective outcome. J Urol 1999; 162: 692.

5 Jarrett TW, Chan DY, Charambura TC, Fugita O and Kavoussi LR: Laparoscopic pyeloplasty: the first 100 cases. J Urol 2002; 167: 1253.

$6 \quad$ Kavoussi LR and Peters CA: Laparoscopic pyeloplasty. J Urol 1993; 150: 1891.

7 Gettman MT, Peschel R, Neururer R and Bartsch G: A comparison of laparoscopic pyeloplasty performed with the daVinci robotic system versus standard laparoscopic techniques: initial clinical results. Eur Urol 2002; 42: 453.

8 Weise ES and Winfield HN: Robotic computer-assisted pyeloplasty versus conventional laparoscopic pyeloplasty. J Endourol 2006; 20: 813.

9 Soroush M and Bagley DH: Ureteroscopic retrograde endopyelotomy. Tech Urol 1998; 4: 77.

10 Bagley DH, Liu JB, Goldberg BB and Grasso M: Endopyelotomy: importance of crossing vessels demonstrated by endoluminal ultrasonography. J Endourol 1995; 9: 465.

11 Bagley DH, Liu JB, Grasso M and Goldberg BB: Endoluminal sonography in evaluation of the obstructed ureteropelvic junction. J Endourol 1994; 8: 287.

12 Ost MC, Kaye JD, Guttman MJ, Lee BR and Smith AD: Laparoscopic pyeloplasty versus antegrade endopyelotomy: comparison in 100 patients and a new algorithm for the minimally invasive treatment of ureteropelvic junction obstruction. Urology 2005; 66: 47.

13 Dimarco DS, Gettman MT, McGee SM, Chow GK, Leroy AJ, Slezak J et al: Longterm success of antegrade endopyelotomy compared with pyeloplasty at a single institution. J Endourol 2006; 20: 707.

14 Neste MG, du Cret RP, Finlay DE, Sane S, Gonzalez R, Boudreau RJ et al: Postoperative diuresis renography and ultrasound in patients undergoing pyeloplasty. Predictors of surgical outcome. Clin Nucl Med 1993; 18: 872.

15 Pohl HG, Rushton HG, Park JS, Belman AB and Majd M: Early diuresis renogram findings predict success following pyeloplasty. J Urol 2001; 165: 2311.

16 Aron M, Desai M, Rubenstein M, Finelli A, Moinzadeh A, Singh D et al: Anterior crossing vessels encountered at laparoscopic pyeloplasty: do they always need 
transposition? Presented at 22nd World Congress of Endourology, Mumbai, India, November 3-6, 2004.

17 Rehman J, Landman J, Sundaram C and Clayman RV: Missed anterior crossing vessels during open retroperitoneal pyeloplasty: laparoscopic transperitoneal discovery and repair. J Urol 2001; 166: 593.

18 Stern JM, Park S, Anderson JK, Landman J, Pearle M and Cadeddu JA: Functional assessment of crossing vessels as etiology of ureteropelvic junction obstruction. Urology 2007; 69: 1022.

19 Rassweiler JJ, Subotic S, Feist-Schwenk M, Sugiono M, Schulze M, Teber D et al: Minimally invasive treatment of ureteropelvic junction obstruction: long-term experience with an algorithm for laser endopyelotomy and laparoscopic retroperitoneal pyeloplasty. J Urol 2007; 177: 1000.

20 Turk IA, Davis JW, Winkelmann B, Deger S, Richter F, Fabrizio MD et al: Laparoscopic dismembered pyeloplasty-the method of choice in the presence of an enlarged renal pelvis and crossing vessels. Eur Urol 2002; 42: 268.

\section{Figures and Tables}

\section{FIG. 1.}

Practice patterns for treatment of UPJO during last decade. Cases from 2007 not included in statistical analysis.

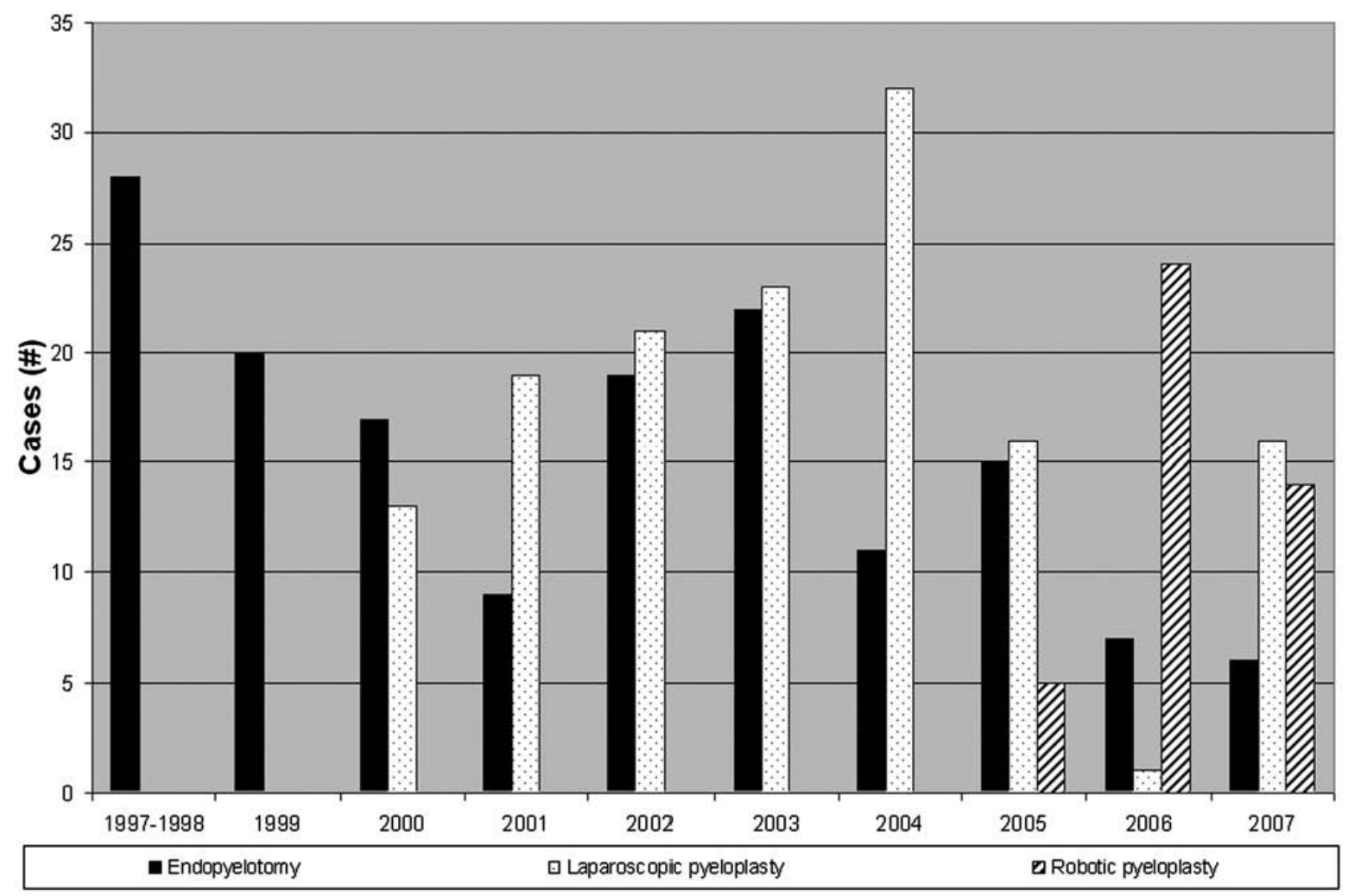


FIG. 2.

Kaplan-Meier estimates of failure-free probability for endopyelotomy and laparoscopic pyeloplasty.

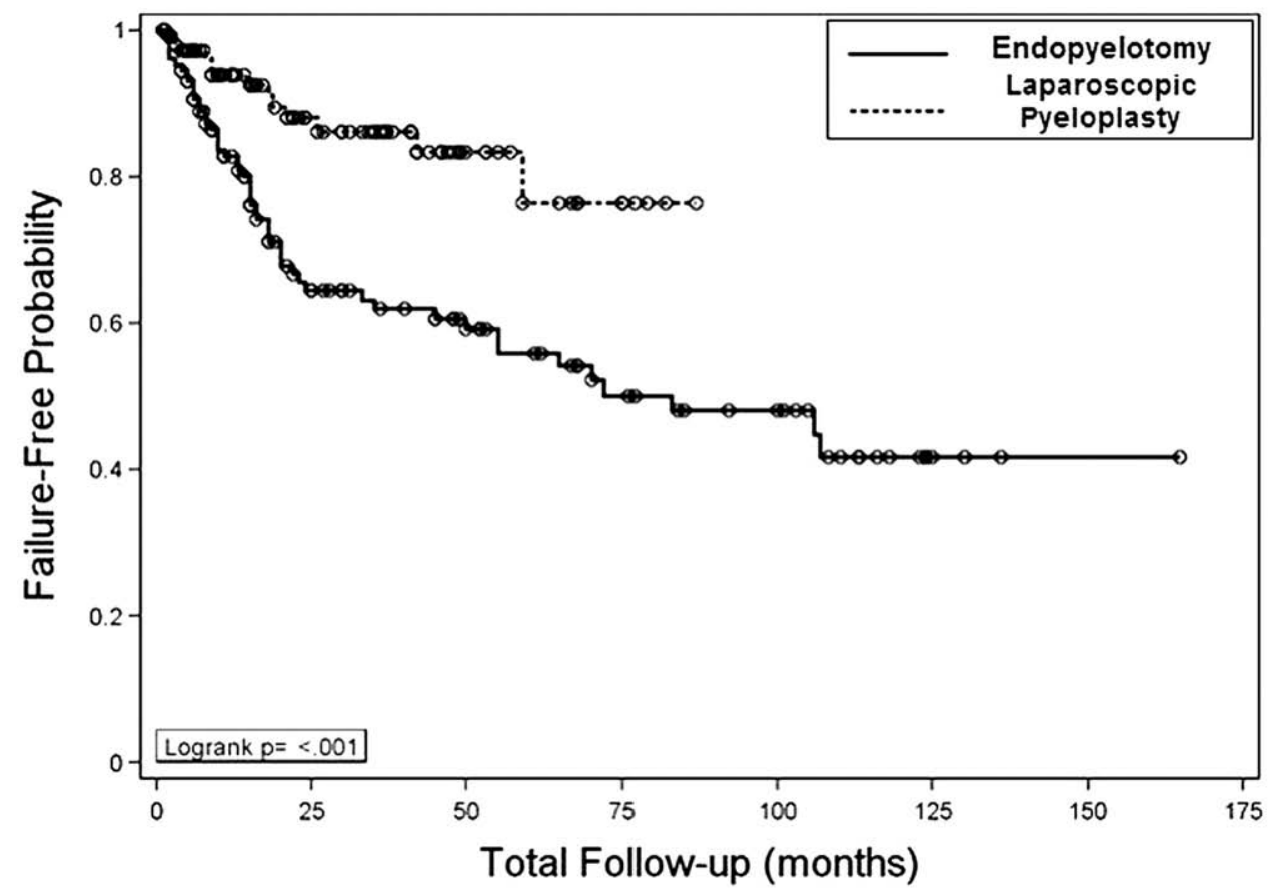

FIG. 3.

Comparative success rates of endopyelotomy and laparoscopic pyeloplasty. Solid line indicates findings of Dimarco et al. ${ }^{13}$ Broken line indicates findings of current study.

Endopyelotomy Success

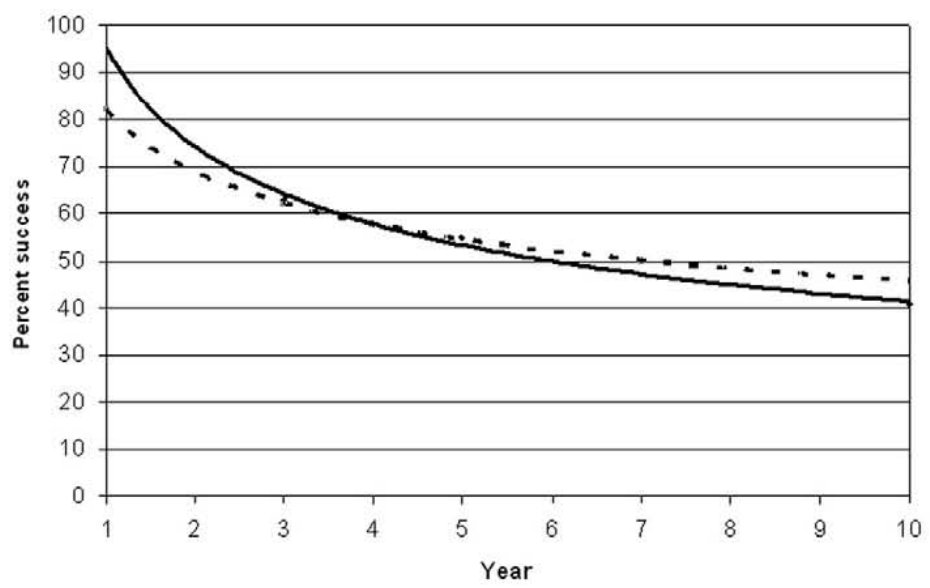

Pyeloplasty Success

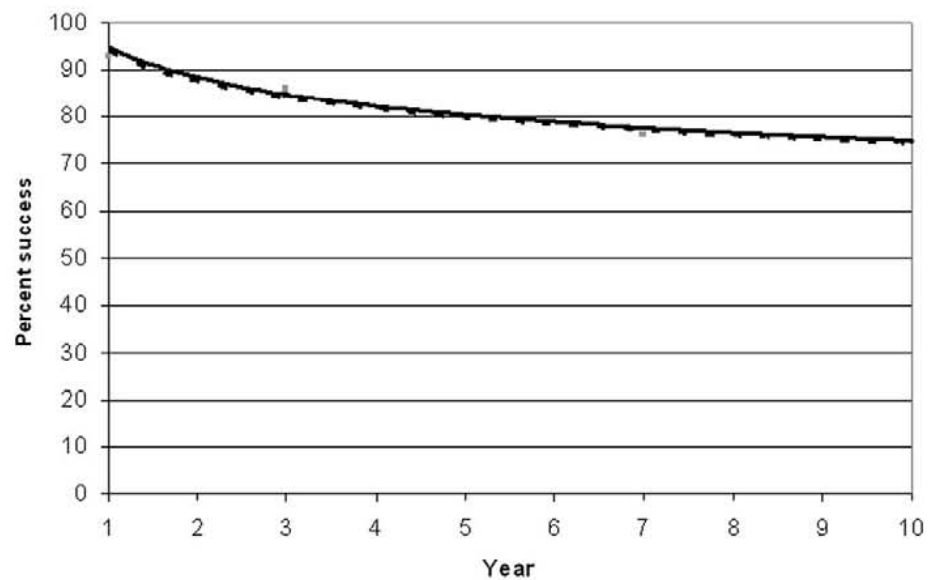


TABLE 1. Patient characteristics

\begin{tabular}{|c|c|c|c|c|}
\hline & \multicolumn{4}{|c|}{ No. (\%) } \\
\hline & Endopyelotomy & LP & $\mathrm{RP}$ & Totals \\
\hline Total pts & 128 & 116 & 29 & 273 \\
\hline \multicolumn{5}{|l|}{ Sex: } \\
\hline Male & 46 (35.9) & $50(44.2)$ & $11(37.9)$ & $107(39.1)$ \\
\hline Female & $82(64.1)$ & 66 (58.4) & $18(62.1)$ & $166(60.9)$ \\
\hline \multicolumn{5}{|l|}{ Crossing vessels:* } \\
\hline Yes & $52(40.6)$ & $80(70.2)$ & $20(69.0)$ & $152(56.1)$ \\
\hline No & 76 (59.4) & $34(29.8)$ & $9(31.0)$ & $119(45.9)$ \\
\hline \multicolumn{5}{|l|}{ High insertion:† } \\
\hline Yes & $78(60.9)$ & $18(30.5)$ & Not available & $96(51.3)$ \\
\hline No & $50(39.1)$ & $41(69.5)$ & Not available & $91(48.7)$ \\
\hline \multicolumn{5}{|l|}{ Repair: } \\
\hline Primary & $91(71.1)$ & $84(72.4)$ & $20(69.0)$ & $195(71.4)$ \\
\hline Secondary & $37(28.9)$ & $32(27.6)$ & $9(31.0)$ & $78(28.6)$ \\
\hline \multicolumn{5}{|l|}{ Prior endopyelotomy: } \\
\hline Yes & $27(21.1)$ & $25(21.6)$ & $9(31.0)$ & $61(22.3)$ \\
\hline No & 101 (78.9) & $91(78.4)$ & $20(69.0)$ & $212(77.7)$ \\
\hline \multicolumn{5}{|l|}{ Prior pyeloplasty: } \\
\hline Yes & $13(10.2)$ & $3(2.6)$ & $0(0.0)$ & $16(5.9)$ \\
\hline No & $115(89.8)$ & $113(97.4)$ & $29(100.0)$ & $157(94.1)$ \\
\hline \multicolumn{5}{|l|}{ Side: } \\
\hline $\mathrm{Rt}$ & $69(53.9)$ & $62(53.4)$ & $18(62.1)$ & $149(54.6)$ \\
\hline Lt & $59(46.1)$ & $54(46.6)$ & $11(37.9)$ & $124(45.4)$ \\
\hline \multicolumn{5}{|l|}{ Age: } \\
\hline Younger than 41 & $73(57.0)$ & $50(43.1)$ & $15(51.7)$ & $138(50.5)$ \\
\hline 41 or Older & $55(43.0)$ & 66 (56.9) & 14 (48.3) & 135 (49.5) \\
\hline \multicolumn{5}{|l|}{ Success: } \\
\hline Yes & 77 (60.2) & $103(88.8)$ & $29(100)$ & 209 (76.6) \\
\hline No & $51(39.8)$ & $13(11.2)$ & $0(0.0)$ & $64(23.4)$ \\
\hline
\end{tabular}


TABLE 2. Cox regression hazard ratios

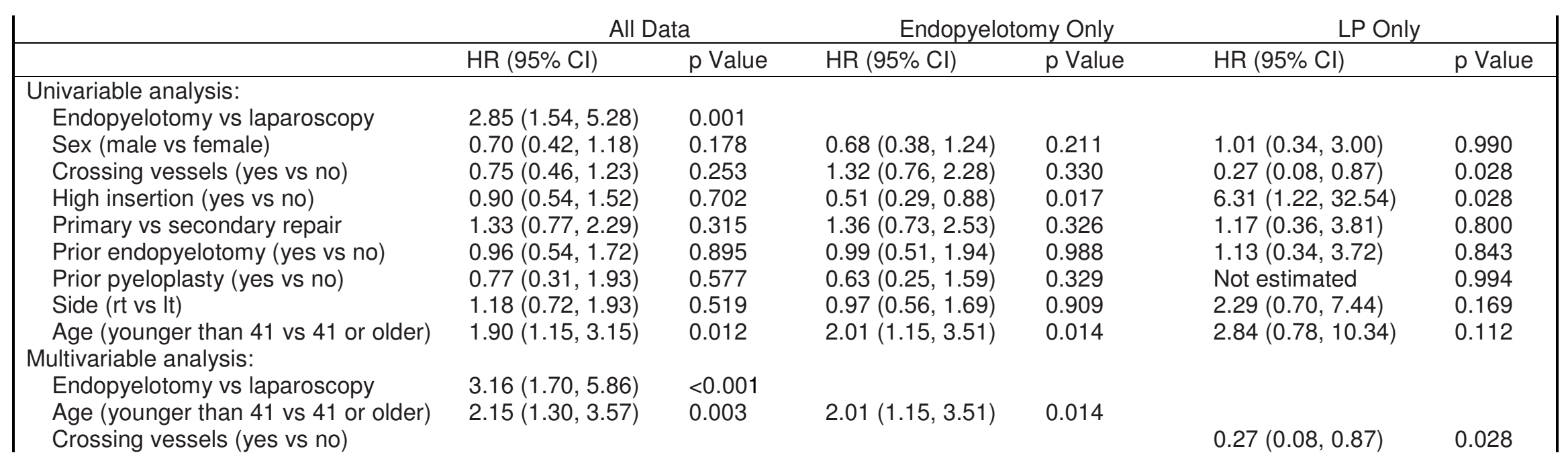

